\title{
Lagrangian simulation and tracking of the mesoscale eddies contaminated by Fukushima-derived radionuclides
}

\author{
Sergey V. Prants, Maxim V. Budyansky, and Michael Y. Uleysky \\ Laboratory of Nonlinear Dynamical Systems, Pacific Oceanological Institute of the Russian Academy of Sciences, \\ 43 Baltiyskaya st., 690041 Vladivostok, Russia \\ Correspondence to: Sergey V. Prants (prants@poi.dvo.ru)
}

Received: 20 December 2016 - Discussion started: 25 January 2017

Revised: 27 April 2017 - Accepted: 12 May 2017 - Published: 14 June 2017

\begin{abstract}
A Lagrangian methodology is developed to simulate, track, document and analyze the origin and history of water masses in ocean mesoscale features. It aims to distinguish whether water masses inside the mesoscale eddies originated from the main currents in the Kuroshio-Oyashio confluence zone. By computing trajectories for a large number of synthetic Lagrangian particles advected by the AVISO velocity field after the Fukushima accident, we identify and track the mesoscale eddies which were sampled in the cruises in 2011 and 2012 and estimate their risk of being contaminated by Fukushima-derived radionuclides. The simulated results are compared with in situ measurements, showing a good qualitative correspondence.
\end{abstract}

\section{Introduction}

High tsunami waves after the Tohoku earthquake on 11 March 2011 damaged the cooling system of the Fukushima Nuclear Power Plant (FNPP). Due to lack of electricity, it was not possible to cool nuclear reactors and the fuel storage pools that caused numerous explosions at the FNPP (for details see Povinec et al., 2013). The Fukushima accident was classified at the maximum level of 7 , similar to the Chernobyl accident which happened in 1986 in the former Soviet Union. Radionuclides were released from the FNPP through two major pathways: direct discharges of radioactive water and atmospheric deposition onto the North Pacific Ocean. Indirect estimation of that deposition is in the range 6.4-35 PBq (Kumamoto et al., 2014). The total amount of
${ }^{137} \mathrm{Cs}$ isotope released into the ocean was estimated to be 3.6 $\pm 0.7 \mathrm{PBq}$ by the end of May 2011 (Tsumune et al., 2013).

A few special research vessel $(\mathrm{R} / \mathrm{V})$ cruises were conducted, just after the accident and later, to measure radioactivity in sea water, zooplankton, fish and in other marine organisms. ${ }^{137} \mathrm{Cs}$ and ${ }^{134} \mathrm{Cs}$ isotopes with 30.17 and 2.06 years half-life, respectively, were detected over a broad area in the western North Pacific in 2011 and 2012 (Honda et al., 2012; Buesseler et al., 2012; Inoue et al., 2012a, b; Tsumune et al., 2012, 2013; Kaeriyama et al., 2013; Oikawa et al., 2013; Aoyama et al., 2013; Kameník et al., 2013; Kumamoto et al., 2014; Kaeriyama et al., 2014; Budyansky et al., 2015). ${ }^{137} \mathrm{Cs}$ concentration levels off Japan before the accident were estimated at the background level to be $1-3 \mathrm{mBq} \mathrm{kg}^{-1}$, while

${ }^{134} \mathrm{Cs}$ was not detectable. Because of a comparatively short half-life time, any measured concentrations of ${ }^{134} \mathrm{Cs}$ could only be Fukushima derived.

The studied area is shown in Fig. 1a. It is known as the Kuroshio-Oyashio confluence zone or a subarctic frontal area (Kawai, 1972). The Kuroshio Extension prolongs the Kuroshio Current which turns to the east at about $35^{\circ} \mathrm{N}$ and flows as a strong meandering jet constituting a front separating the warm subtropical and cold subarctic waters. It is a region with one of the most intense air-sea heat exchange and the highest eddy kinetic-energy level. The KuroshioOyashio confluence zone is populated with several mesoscale eddies that transfer heat, salt, nutrients, carbon, pollutants and other tracers across the ocean. They originate, besides from the Kuroshio Extension, from the Tsugaru Warm Current, flowing between the Honshu and Hokkaido islands, and from the cold Oyashio Current flowing out of the Arctic along the Kamchatka Peninsula and the Kuril Islands 


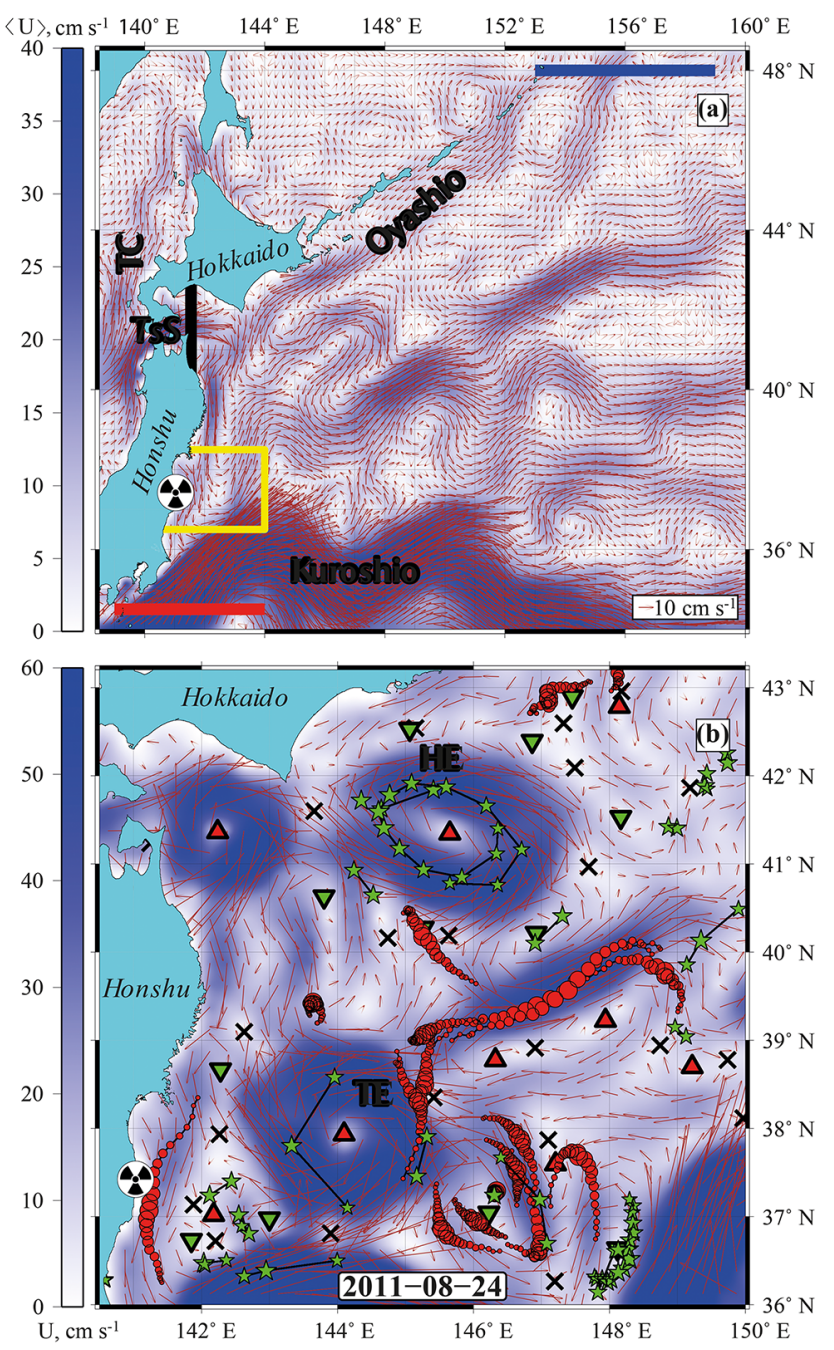

Figure 1. (a) The AVISO velocity field in the Kuroshio-Oyashio confluence zone, averaged from 1993 to 2016. TsS stands for the Tsugaru Strait. Location of the FNPP is shown by the radioactivity sign. The area just around the FNPP is shown by the yellow lines. (b) The velocity field on 24 August, 2011, with the Tohoku (TE) and Hokkaido (HE) eddies studied in the paper and with tracks of some available drifters (the red circles) and Argo floats (the green stars) present in the area at that time. Elliptic and hyperbolic stagnation points with zero mean velocity are indicated by triangles and crosses, respectively, with upward- and downward-oriented triangles denoting anticyclones and cyclones, respectively.

(Fig. 1a). The lifetime of those eddies ranges from a few weeks to a few years.

The standard approach in simulating transport phenomena, such as propagation of oil after the explosion at the Blue Horizon mobile drilling rig in the Gulf of Mexico in April 2010 and propagation of radioactive isotopes after the accident at the FNPP, is to run global or regional numerical models of circulation to simulate propagation of pollutants and try to forecast their trajectories. The outcomes pro- vide "spaghetti-like" plots of individual trajectories which are hard to interpret. Moreover, as the majority of real trajectories in a chaotic environment are very sensitive to small and inevitable variations in initial conditions, they are practically unpredictable even over a comparatively short time.

A specific Lagrangian approach, based on dynamical systems theory, has been developed in recent decades with the aim of finding more or less robust material structures in chaotic flows governing mixing and transport of Lagrangian particles and creating transport barriers preventing propagation of a contaminant across them (for reviews see Samelson and Wiggins, 2006; Mancho et al., 2006; Koshel' and Prants, 2006; Haller, 2015). Identification of such structures in the ocean would help to predict, for short and medium-length periods of time, where a contaminant will move even without a precise solution of the Navier-Stokes equations. This approach has been successfully used in simulating propagation of oil in the Gulf of Mexico (Mezić et al., 2010; Huntley et al., 2011; Olascoaga and Haller, 2012) and propagation of Fukushima-derived radionuclides in the Pacific ocean (Prants et al., 2011b; Budyansky et al., 2015; Prants et al., 2014).

The present authors have developed a set of Lagrangian tools for tracking the origin, history and fate of water masses advected by analytic, altimetric and numerical velocity fields generated by eddy-resolved regional circulation models (Budyansky et al., 2009; Prants et al., 2011a, b; Prants, 2013; Prants et al., 2013; Prants, 2014; Budyansky et al., 2015). Each elementary volume of water can be attributed to physico-chemical properties (temperature, salinity, density, radioactivity, etc.) which characterize this volume as it moves. In addition, each water parcel can be attributed to other types of diagnostics which are exclusively a function of its trajectory. We call them "Lagrangian indicators". They are, for example, distance traveled by a fluid particle for some period of time; absolute, zonal and meridional displacements of particles from their original positions; the number of their cyclonic and anticyclonic rotations; time of residence of fluid particles inside a given area; exit time out off that area; and the number of times particles visited different places in a studied region.

The Lagrangian indicators contain information about the origin, history and fate of the corresponding water masses and allow the identification of water masses that move coherently, either by propagating together or by rotating together. Even if adjacent waters are indistinguishable, say, by temperature (e.g., the satellite SST images indicate no thermal front), the corresponding water masses could still be distinguishable by, for example, their origin, traveling history and other factors. The Lagrangian indicators are computed by integrating advection equations (Eq. 1) for a large number of synthetic particles forward and backward in time. When integrating Eq. (1) forward in time, one computes particle trajectories to know the fate of the corresponding particles, and when integrating Eq. (1) backward in time, one could know where the particles came from and the history of their travel. 
The purpose of this paper is threefold. Firstly, we develop a Lagrangian methodology in order to track and document the origin and history of water masses constituting prominent mesoscale features. It allows the distinction of water masses inside mesoscale eddies originating from the main currents in the Kuroshio-Oyashio confluence zone. Secondly, we apply that methodology in order to identify and track the mesoscale eddies, advected by the altimetric AVISO velocity field, with a risk of being contaminated by Fukushima-derived radionuclides. Finally, the simulation results are compared qualitatively with in situ sampling of those eddies in the R/V cruises. The location and form of the simulated eddies are verified, when possible, by tracks of surface drifters and diving Argo floats available at the sites aoml.noaa.gov/phod/dac and www.argo.net, respectively.

\section{Data and methodology}

All the simulation results are based on integrating equations of motion for a large number of synthetic particles (tracers) advected by the AVISO velocity field.

$$
\frac{d \lambda}{\mathrm{d} t}=u(\lambda, \varphi, t), \quad \frac{\mathrm{d} \varphi}{\mathrm{d} t}=v(\lambda, \varphi, t),
$$

where $u$ and $v$ are angular zonal and meridional velocities, and $\varphi$ and $\lambda$ are latitude and longitude, respectively. The altimetry-based velocities were obtained from the AVISO database (aviso.altimetry.fr) archived daily on a $1 / 4^{\circ} \times 1 / 4^{\circ}$ grid. The velocity field was interpolated using a bicubical spatial interpolation and third-order Lagrangian polynomials in time. In integrating Eq. (1) we used a fourth-order RungeKutta scheme with an integration step of 0.001 days.

The velocity field is from altimetry data, which provide the geostrophical component of the real near-surface velocities valid at the mesoscale. In order to display the enormous amount of information, we plot maps of specific Lagrangian indicators versus particle's initial positions. The region under study is seeded with a large number of Lagrangian particles whose trajectories are computed for a given period of time. The results obtained are processed to get a data file with the field of a specific Lagrangian indicator in this area. Finally, its values are coded by color and represented as a map in geographic coordinates.

It is informative also to identify "instantaneous" stagnation elliptic and hyperbolic points on the Lagrangian maps. We mark them by triangles and crosses, respectively. They are points with zero velocity which are computed daily with the AVISO velocity field. The elliptic points are called stable and the hyperbolic ones are unstable. Their local stability properties are characterized by a standard method calculating eigenvalues of the Jacobian matrix of the velocity field. The elliptic points, situated mainly in the centers of eddies, are those points around which the motion is stable and circular. Upward (downward) orientation of one of the triangle's top on the maps means anticyclonic (cyclonic) rotations of water around them. The hyperbolic points, situated mainly between and around eddies, have stable manifolds along which water parcels converge to such a point and unstable manifolds along which they diverge. The stagnation points are moving Eulerian features and may undergo bifurcations in the course of time. In spite of nonstationarity of the velocity field, some of them may exist for weeks and much more. The hyperbolic points and their attracting and repelling manifolds were recently identified with the help of drifter's tracks in the Gulf of La Spezia in the northwestern Mediterranean Sea (Haza et al., 2010), in the Gulf of Lion (Nencioli et al., 2011), in the Gulf of Mexico (Olascoaga et al., 2013) and in the northwestern Pacific (Prants et al., 2016).

The altimetry-based Lagrangian maps allow accurate identification and tracking of mesoscale eddies and document their transformation due to interactions with currents and other eddies. Inspecting daily-computed Lagrangian maps for a long period of time (up to 2 years in this paper) and computing stagnation elliptic points daily, one can track the origin and fate of water masses within a given eddy if it is sufficiently large and long lived (i.e., more than a week). For this purpose Lagrangian diagnostics are more appropriate than commonly used Eulerian techniques, because Lagrangian maps are imprints of the history of water masses involved in the vortex motion, whereas vorticity, Okubo-Weiss parameter and similar indicators are only instantaneous snapshots (see Olascoaga et al., 2013, and Prants et al., 2016, for comparison).

Being motivated by the problem of identification of Fukushima-contaminated waters in the core and at the periphery of persistent mesoscale eddies in the area, we develop in this paper a specific Lagrangian technique designed to distinguish water masses of a different origin inside the eddies with a risk of being contaminated. With this aim we specify, besides Fukushima-derived waters, water masses originated from the main currents in the Kuroshio-Oyashio confluence zone. The integration was performed backward in time. We removed from consideration all the particles entered into any AVISO grid cell with two or more corners touching the land in order to avoid artifacts due to the inaccuracy of the altimetry-based velocity field near the coast.

In what follows, we define the "yellow" waters on the maps as those which have a large risk of being contaminated because they came after the accident from the area just around the FNPP, enclosed by the yellow straight lines in Fig. 1a, for the period from the day of the accident, March 11, 2011, to May 18, 2011, when direct releases of radioactive isotopes to the ocean and atmosphere stopped. The "red" waters are salty and warm Kuroshio waters. To be more exact, they came from the red zonal line $\left(34.5^{\circ} \mathrm{N}, 139-144^{\circ} \mathrm{E}\right)$ in Fig. 1a, crossing the Kuroshio main jet. The "black" waters came from the warm Tsushima Current flowing via the Tsugaru Strait out off the Japan Sea and across that strait (the black line with $40-43^{\circ} \mathrm{N}, 141.55^{\circ} \mathrm{E}$ ). The "blue" waters 

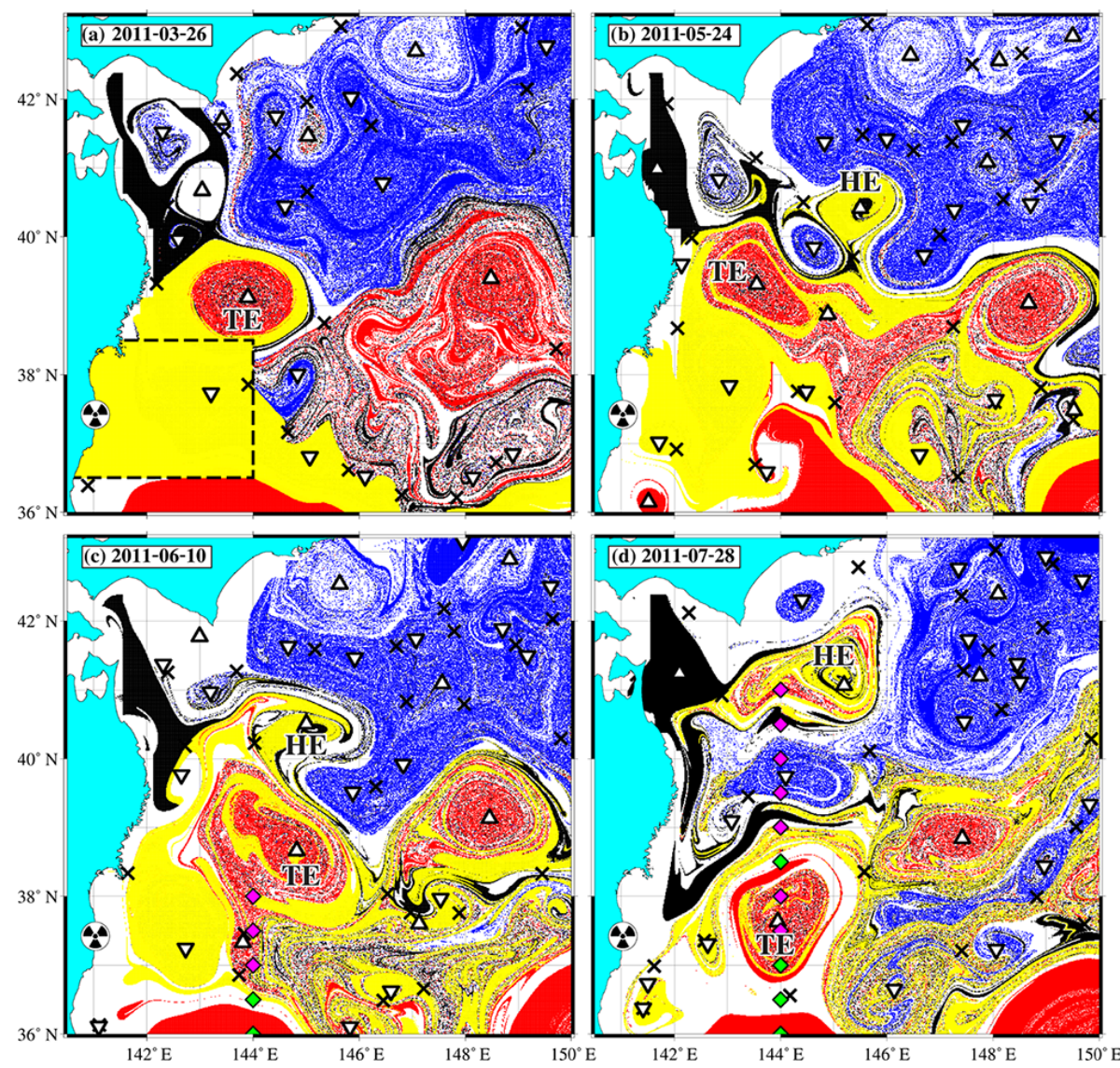

Figure 2. The Lagrangian maps show evolution of the Tohoku eddy (TE) from after the accident to the days of its sampling and the origin of waters in its core and at the periphery. The red, black and blue colors specify the tracers which came for 2 years in the past to their places on the maps from the Kuroshio, Oyashio and Tsushima currents, respectively, more exactly, from the corresponding line segments shown in Fig. 1a. The yellow color marks the Lagrangian particles coming from the area around the FNPP in Fig. 1a (shown in Fig. 2a by the dashed line), after the day of the accident on 11 March 2011. The TE was sampled on 10 and 11 June 2011 by Buesseler et al. (2012) along the transect $35.5-38^{\circ} \mathrm{N}, 144^{\circ} \mathrm{E}$ shown in (c) and at the end of July 2011 by Kaeriyama et al. (2013) along the transect $35^{\circ} \mathrm{N}-41^{\circ} \mathrm{N}, 144^{\circ} \mathrm{E}$ shown in (d). The locations of stations with surface seawater samples (collected by Buesseler et al., 2012 and Kaeriyama et al., 2013) with measured radiocesium concentrations at the background level are indicated by the green diamonds. Stations where the concentrations were measured to be much higher are marked by the magenta diamonds.

are fresher and colder waters originating from the Oyashio Current and crossing the blue zonal line $\left(48^{\circ} \mathrm{N}, 153-159^{\circ} \mathrm{E}\right)$ shown in Fig. 1a. The "white" waters on the Lagrangian maps have not been specified as originating from one of the segments mentioned above. They could reach their places on the maps from anywhere besides those segments.

We are interested in advective transport for a comparatively long period of time, up to 2 years. It is hardly possible to adequately simulate motion of a specified passive particle in a chaotic flow, but it is possible to reproduce transport of a statistically significant number of particles. Our results are based not on simulation of individual trajectories but on statistics for 490000 Lagrangian particles. We cannot, of course, guarantee that we compute "true" trajectories for individual particles. The description of the general pattern of transport for half a million particles is much more robust.
However, we do not try to quantitatively simulate the concentration of radionuclides or estimate the content of water masses of different origin inside the studied eddies.

\section{Results}

A few mesoscale eddies were present in the studied area on the day of the accident. The cyclonic eddies with the centers, marked by the downward-oriented triangles on the Lagrangian maps, prevailed in the area to the north of the Subarctic Front, the boundary between the subarctic (blue) and subtropical (red) waters in Fig. 2. The anticyclonic eddies with the centers, marked by the upward-oriented triangles, prevailed to the south of the front. 
The large anticyclonic Tohoku eddy (TE,) with the center at around $39^{\circ} \mathrm{N}, 144^{\circ} \mathrm{E}$ in March 2011, was sampled after the accident in the two R/V cruises in June (Buesseler et al., 2012) and July 2011 (Kaeriyama et al., 2013), showing large concentrations of ${ }^{137} \mathrm{Cs}$ and ${ }^{134} \mathrm{Cs}$. The anticyclonic Hokkaido eddy (HE), genetically connected with the TE, originated in the middle of May 2011 with the center at around $40^{\circ} \mathrm{N}, 145^{\circ} \mathrm{E}$. After that it captured some contaminated water from the TE. It was sampled at the end of July 2011 (Kaeriyama et al., 2013).

The anticyclonic Tsugaru eddy (TsE) was genetically connected with the HE. It originated in the beginning of February 2012 with the center at around $41.9^{\circ} \mathrm{N}, 148^{\circ} \mathrm{E}$ and captured some contaminated water from the HE. The TsE was sampled in the R/V Professor Gagarinskiy cruise on 5 July, 2012, and found to have concentrations of ${ }^{137} \mathrm{Cs}$ and ${ }^{134} \mathrm{Cs}$ over the background level at the surface and at intermediate depths (Budyansky et al., 2015). All these eddies will be studied in this section from the Lagrangian point of view in order to simulate and track by which transport pathways they could have gained water masses from the Fukushima area or from other origins and to compare qualitatively the simulation results with in situ measurements.

\subsection{The Tohoku eddy}

We tracked with daily-computed Lagrangian maps the birth, metamorphoses and decay of the mesoscale anticyclonic TE. It originated in the middle of May 2010 with the elliptic point at around $38^{\circ} \mathrm{N}, 144^{\circ} \mathrm{E}$ at that time as the result of interaction of a warm anticyclonic Kuroshio ring with a cyclone with mixed Kuroshio and Oyashio core waters. It has interacted with other eddies almost for a year, with multiple splitting and merging in the area to the east off the Honshu Island. Just after the accident, it began to gain yellow water from the area around the FNPP with a high risk of contamination. That eddy is clearly seen in an earlier simulation just after the accident in Fig. 3b by Prants et al. (2011b) and on the Lagrangian map in Fig. 2a as a red patch labeled as TE with the center at $39^{\circ} \mathrm{N}, 144^{\circ} \mathrm{E}$ on 26 March 2011.

The maps in Fig. 2 and in the subsequent figures were computed, as was explained in Sect. 2. The red color in the core of the TE means that its core water was of subtropical origin. More precisely, the red tracers were advected for 2 years from the red line segment in Fig. 1a to the current place on the map. In March 2011 yellow water, coming from the area around the FNPP with a comparatively high risk of being contaminated, wrapped round the TE. A thin streamer of Tsugaru black water, coming from the black line segment in Fig. 1a, wrapped a periphery of the TE at the end of March. Yellow waters propagated gradually to the east and south due to a system of currents wrapping around the eddies present in the area. The straight zonal boundary along $36.5^{\circ} \mathrm{N}$ and meridional boundary along $144^{\circ} \mathrm{E}$, separating water masses of different origin in Fig. 2a on 26 March 2011, are just fragments of the boundary in Fig. 1a restricting the area around the FNPP. These boundaries separate the yellow tracers which were present within the area from those which have not yet managed to penetrate inside the area for 15 days after the accident.

In April and May 2011 the TE had a sandwich-like structure, with the red subtropical core belted with a narrow streamer of Fukushima yellow waters which, in turn, was encircled by a red streamer of Kuroshio subtropical water (Fig. 2b). A new eddy configuration appeared at the end of May in Fig. 2b, with the TE interacting with a blue cyclone with the center at $39.9^{\circ} \mathrm{N}, 144.7^{\circ} \mathrm{E}$ and a newborn yellow anticyclone which we call the Hokkaido eddy with the center at $40.4^{\circ} \mathrm{N}, 145.5^{\circ} \mathrm{E}$. The core of that cyclone consisted of a blue subarctic Oyashio water with low risk of being contaminated, but the HE core water came from the area around the FNPP with a high risk of being contaminated.

In the course of time the TE moved gradually to the south. Its periphery was sampled at the beginning of June by Buesseler et al. (2012), and the whole eddy was crossed at the end of July 2011 by Kaeriyama et al. (2013). Fukushimaderived cesium isotopes were measured on 10 and 11 June during the R/V Ka'imikai-o-Kanaloa cruise (Buesseler et al., 2012) along the $144^{\circ} \mathrm{E}$ meridional transect where the cesium concentrations were found to be in the range from the background level, $C_{137}=1.4-3.6 \mathrm{mBq} \mathrm{kg}^{-1}$ (stations 13 and 14), to a high level up to $C_{137}=173.6 \pm 9.9 \mathrm{mBq} \mathrm{kg}^{-1}$ (station 10). The ratio ${ }^{134} \mathrm{Cs} /{ }^{137} \mathrm{Cs}$ was close to 1 .

For ease of comparison, we mark, with the green diamonds in Fig. 2c, the locations of stations 13 and 14 with collected surface seawater samples by Buesseler et al. (2012) in which the cesium concentrations were measured to be at the background level $\left(\lesssim 3.6 \mathrm{mBq} \mathrm{kg}^{-1}\right)$. The stations 10,11 and 12 , where the concentrations were found to be much larger, are indicated by the magenta diamonds. Our simulation in Fig. 2c shows that stations 13 and 14 on the days of sampling were located in red and white waters with a low risk of containing Fukushima-derived radionuclides.

Transport and mixing at and around stations 10, 11 and 12 with high measured values of the cesium concentrations (Buesseler et al., 2012) were governed mainly by the interaction of the TE with the yellow mesoscale cyclone with the center at $37.2^{\circ} \mathrm{N}, 142.8^{\circ} \mathrm{E}$. This cyclone formed in the area in April and captured yellow waters with a high risk of contamination. Unfortunately, it has not been sampled in the R/V Ka'imikai-o-Kanaloa cruise. The surface seawater samples at stations 10,11 and 12 were collected on the days of sampling at the eastern periphery of that cyclone and at the southern periphery of the TE with the yellow streamer there. Station 10, with the highest measured level of the ${ }^{137} \mathrm{Cs}$ concentration of $C_{137}=173.6 \pm 9.9 \mathrm{mBq} \mathrm{kg}^{-1}$, was located at $38^{\circ} \mathrm{N}, 144^{\circ} \mathrm{E}$ inside the wide streamer of yellow water around the TE. Stations 11 and 12, with $C_{137}=$ $103.7 \pm 5.9 \mathrm{mBq} \mathrm{kg}^{-1}$ and $C_{137}=93.6 \pm 4.9 \mathrm{mBq} \mathrm{kg}^{-1}$, respectively, were located within the narrow streamers with 
yellow simulated water in Fig. 2c intermitted with narrow streamers of red water. So, we estimate the likelihood of finding Fukushima-derived radionuclides there (the magenta diamonds) to be much higher than at stations 13 and 14 (the green diamonds), and it is confirmed by a qualitative comparison with measured data.

A specific configuration of mesoscale eddies occurred in the area to the northeast of the FNPP at the end of July 2011, the days of sampling by Kaeriyama et al. (2013) along the $144^{\circ} \mathrm{E}$ meridian from 35 to $41^{\circ} \mathrm{N}$ during the R/V Kaiun maru cruise. That transect is shown in Fig. 2d. It crosses the TE and the cyclone with blue Oyashio water, which is genetically linked to the blue cyclone at $39.9^{\circ} \mathrm{N}$, $144.7^{\circ} \mathrm{E}$ in Fig. $2 \mathrm{~b}$. The transect also partly crosses the periphery of the anticyclonic HE. The measured ${ }^{137} \mathrm{Cs}$ concentrations in surface seawater samples at the stations C43-C55 were found to be in the range from the background level, $1.9 \pm 0.4 \mathrm{mBq} \mathrm{kg}^{-1}$ (station C52), to a much higher level of $153 \pm 6.8 \mathrm{mBq} \mathrm{kg}^{-1}$ (station C47). The colored tracking maps in Fig. 5 by Prants et al. (2014) show where the simulated tracers of that transect were moving from 11 March to 10 April, 2011, being advected by the AVISO velocity field.

The risk of radioactive contamination of the markers placed at $36-36.5^{\circ} \mathrm{N}$ was estimated by Prants et al. (2014), to be small, because they were advected mainly by the Kuroshio Current from the southwest to the east (the corresponding concentrations were measured by Kaeriyama et al., 2013, to be $\left.2-5 \mathrm{mBq} \mathrm{kg}^{-1}\right)$. The present simulation in Fig. $2 \mathrm{~d}$ also shows that stations C51, 52 and 53 (the green diamonds), with the measured cesium concentrations at the background level on the days of sampling by Kaeriyama et al. (2013) were located in the red waters (stations C51 and C53) advected by the main Kuroshio jet from the southwest and in the white waters (station C52) between the TE and the jet. Therefore, we estimate the likelihood of finding Fukushimaderived radionuclides there to be comparatively low.

The transect $36.5-38^{\circ} \mathrm{N}$ in Fig. $2 d$ (the red one in Fig. 5 by Prants et al., 2014) crossed the TE. The ${ }^{137} \mathrm{Cs}$ concentrations at the stations $\mathrm{C} 49$ and $\mathrm{C} 50$ of that transect were measured to be $36 \pm 3.3$ and $50 \pm 3.6 \mathrm{mBq} \mathrm{kg}^{-1}$ (Kaeriyama et al., 2013). Comparing those results with simulated ones, we note the presence of yellow water in the TE core at the locations of those stations. Surface samples at station $\mathrm{C} 48\left(38.5^{\circ} \mathrm{N}\right)$ were measured to contain the ${ }^{137} \mathrm{Cs}$ concentration to be at the background level $2.7 \pm 0.6 \mathrm{mBq} \mathrm{kg}^{-1}$ (Kaeriyama et al., 2013). The corresponding green diamond is located in our simulation in the area with red and white waters.

Inspecting the Lagrangian maps on the days between 6 June and 28 July (not shown), we have found that the yellow cyclone with the center at $37.2^{\circ} \mathrm{N}, 142.8^{\circ} \mathrm{E}$ in Fig. $2 \mathrm{c}$ collapsed at the end of June. Its yellow core water with a high risk of being contaminated was wrapped around the neighbor anticyclone TE in the form of a wide yellow streamer visible in Fig. 2d. The highest concentration, $C_{137}=153 \pm$ $6.8 \mathrm{mBq} \mathrm{kg}^{-1}$, was measured by Kaeriyama et al. (2013) at station $\mathrm{C} 47\left(39^{\circ} \mathrm{N}\right)$, situated in the area of that streamer. Stations $\mathrm{C} 46\left(39.5^{\circ} \mathrm{N}\right)$ with $C_{137}=83 \pm 5.0 \mathrm{mBq} \mathrm{kg}^{-1}$ is situated in the close proximity to a yellow streamer sandwiched between white and black waters.

A comparatively high concentration, $\quad C_{137}=$ $65 \pm 4.3 \mathrm{mBq} \mathrm{kg}^{-1}$, was measured by Kaeriyama et al. (2013) at station $\mathrm{C} 45\left(40^{\circ} \mathrm{N}\right)$ during the days of sampling in the core of the blue cyclone with the center at $39.7^{\circ} \mathrm{N}$, $144.2^{\circ} \mathrm{E}$ (Fig. 2d). Our simulation shows that it was formed mainly by Oyashio blue waters (with a low risk of being contaminated by Fukushima-derived radionuclides) and partly by white waters.

When comparing simulation results in Fig. $2 d$ with the measurements by Kaeriyama et al. (2013), we have found that the simulation is consistent with samplings at stations C48, 51, 52 and 53 in the sense that the cesium concentrations were measured to be at the background level in those places on the maps where there is no signs of yellow water with a high risk of containing Fukushima-derived radionuclides. Our simulation is also consistent, at least quantitatively, with samplings at stations C47, 49 and 50 with high measured levels of the cesium concentrations because the yellow water is present there in our simulation.

However, there is an inconsistency of simulation with samplings at stations $\mathrm{C} 45$ and $\mathrm{C} 46$, where there are practically no yellow tracers but rather only blue and white ones. The reasons for this inconsistency might be different. In this paper we track only those tracers which originated from the blue, red and black segments as well as the yellow rectangular around the FNPP shown in Fig. 1a. So we did not specify the origin of white waters. They could reach their places on the maps from anywhere besides those segments and the area around the FNPP. They could in principle contain Fukushima-derived radionuclides that were deposited at the sea surface from the atmosphere after the accident and then advected by eddies and currents in the area. Moreover, they could be those tracers which were located inside AVISO grid cells near the coast around the FNPP just after the accident and were then advected outside. We removed from consideration all the tracers entered into any AVISO grid cell with two or more corners touching the land because of inaccuracy of the altimetry-based velocity field there and in order to avoid artifacts.

Thus, the white streamers inside the core and at the periphery of the blue cyclone with the center at $39.7^{\circ} \mathrm{N}, 144.2^{\circ} \mathrm{E}$ (nearby stations C45 and C46 with high measured concentrations of cesium by Kaeriyama et al., 2013) could, in principle, contain contaminated water. However, it has not been proved in our simulation due to the above-mentioned reasons.

\subsection{The Hokkaido eddy}

Now we consider the anticyclonic HE. It originated in the middle of May (see the yellow patch in Fig. $2 \mathrm{~b}$ with the cen- 


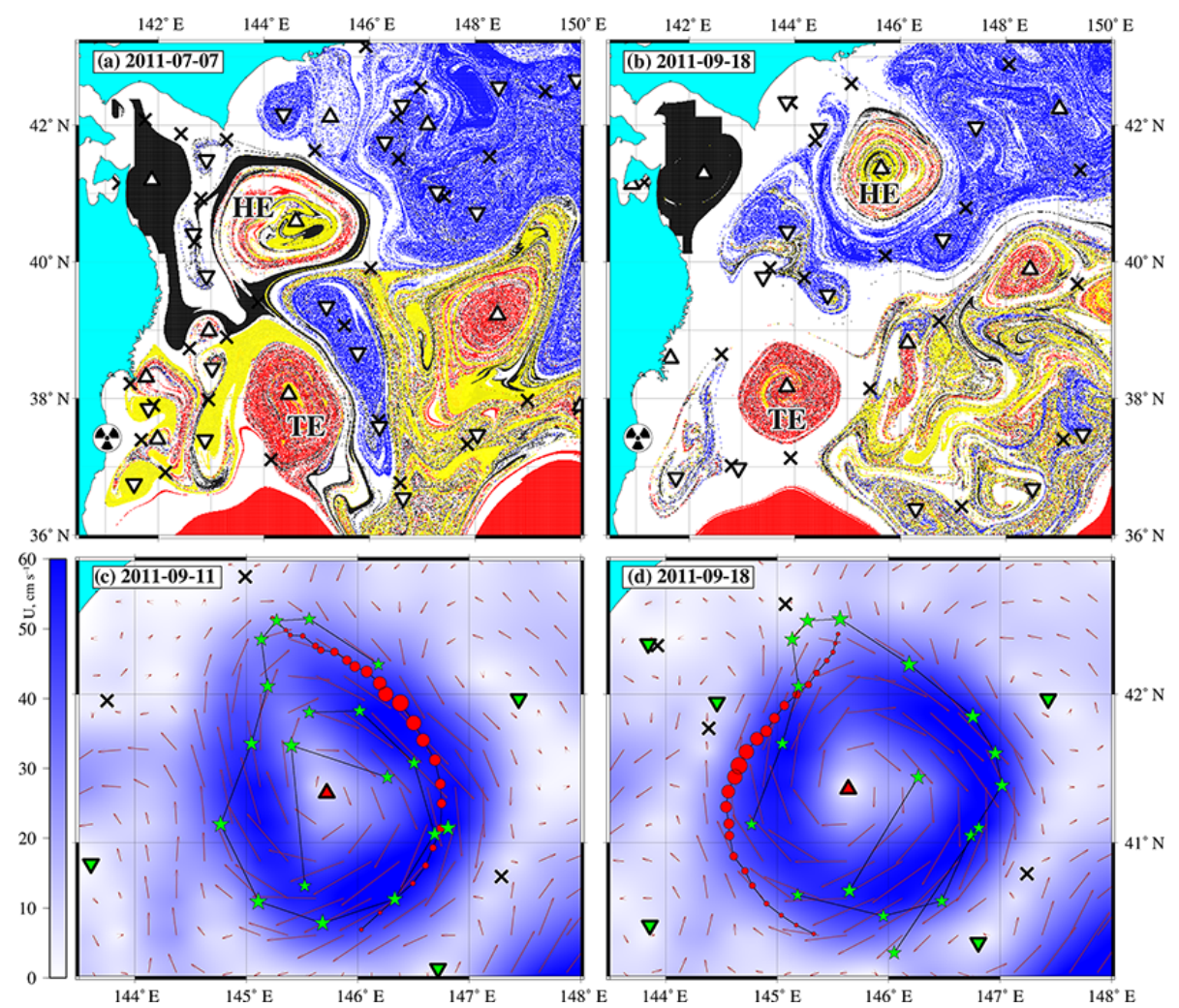

Figure 3. (a)-(b) The Lagrangian maps show evolution of the Hokkaido eddy (HE) after the FNPP accident to the days of its sampling and the origin of waters in its core and at the periphery. (c)-(d) A fragment of the track of the drifter no. 39123 is indicated by the full circles for 3 days before the day indicated with the size of circles increasing in time. Tracks of three Argo floats are shown by the stars. The largest star corresponds to the day indicated and the other ones each show float positions 7 days before and after that date.

ter at $40.3^{\circ} \mathrm{N}, 145.5^{\circ} \mathrm{E}$ ), being genetically linked to the TE. During May, the TE gradually lost a Fukushima yellow water from its periphery to form the core of the HE. Fig. 3a shows the HE with a yellow core surrounded by modified subtropical red water which, in turn, is surrounded by Tsugaru black water.

The sampling of that eddy and its periphery by Kaeriyama et al. (2013) along the $144^{\circ} \mathrm{E}$ meridian at the end of July showed comparatively high concentrations of $C_{137}=60 \pm$ 4.0 and $71 \pm 4.6 \mathrm{mBq} \mathrm{kg}^{-1}$ at stations $\mathrm{C} 44\left(40.5^{\circ} \mathrm{N}\right)$ and $\mathrm{C} 43$ $\left(41^{\circ} \mathrm{N}\right)$, respectively. Station C43 was located inside the anticyclone HE filled mainly by yellow waters, and we estimate the likelihood of finding Fukushima-derived radionuclides there to be large. Station C44 was located at the southern periphery of the anticyclone $\mathrm{HE}$ at the boundary between white and blue waters but in close proximity to a yellow streamer.

The location of the HE on 24 August 2011 is shown in the AVISO velocity field in Fig. 1b. To verify the simulated locations of the $\mathrm{HE}$ and its form, we plot in Fig. 3c and $d$ fragments of the tracks of a drifter and three Argo floats captured by that eddy in September 2011. A fragment of the track of the drifter no. 39123 is shown by the red circles with the size increasing in time for 3 days be- fore the dates indicated in Figs. 3c and d and decreasing for 3 days after those dates, i.e., the largest circle corresponds to the drifter position at the indicated date. It was launched after the accident on 18 July 2011 at the point $45.588^{\circ} \mathrm{N}$, $151.583^{\circ} \mathrm{E}$ in the Oyashio Current, advected by the current to the south and eventually captured by the HE moving around clockwise. Fragments of the clockwise tracks of the three Argo floats are shown by stars in Fig. 3c and d for 7 days before and 7 days after the indicated dates. The float no. 5902092 was released long before the accident on September 9,2008 at the point $32.699^{\circ} \mathrm{N}, 145.668^{\circ} \mathrm{E}$ to the south of the Kuroshio Extension jet and was able to cross the jet and go far north. The float no. 2901019 was released before the accident on 19 April 2010 at the point $41.723^{\circ} \mathrm{N}$, $146.606^{\circ} \mathrm{E}$. The float no. 2901048 was released just after the accident on 10 April 2011 at the point $37.469^{\circ} \mathrm{N}, 141.403^{\circ} \mathrm{E}$ nearby the FNPP.

Our simulation shows that the HE contained, after its formation in the middle of May 2011, a large amount of yellow water probably contaminated by the Fukushima-derived radionuclides. This conclusion is supported by an increased concentration of radiocesium measured in its core at station C43 by Kaeriyama et al. (2013) at the end of July 2011. The 

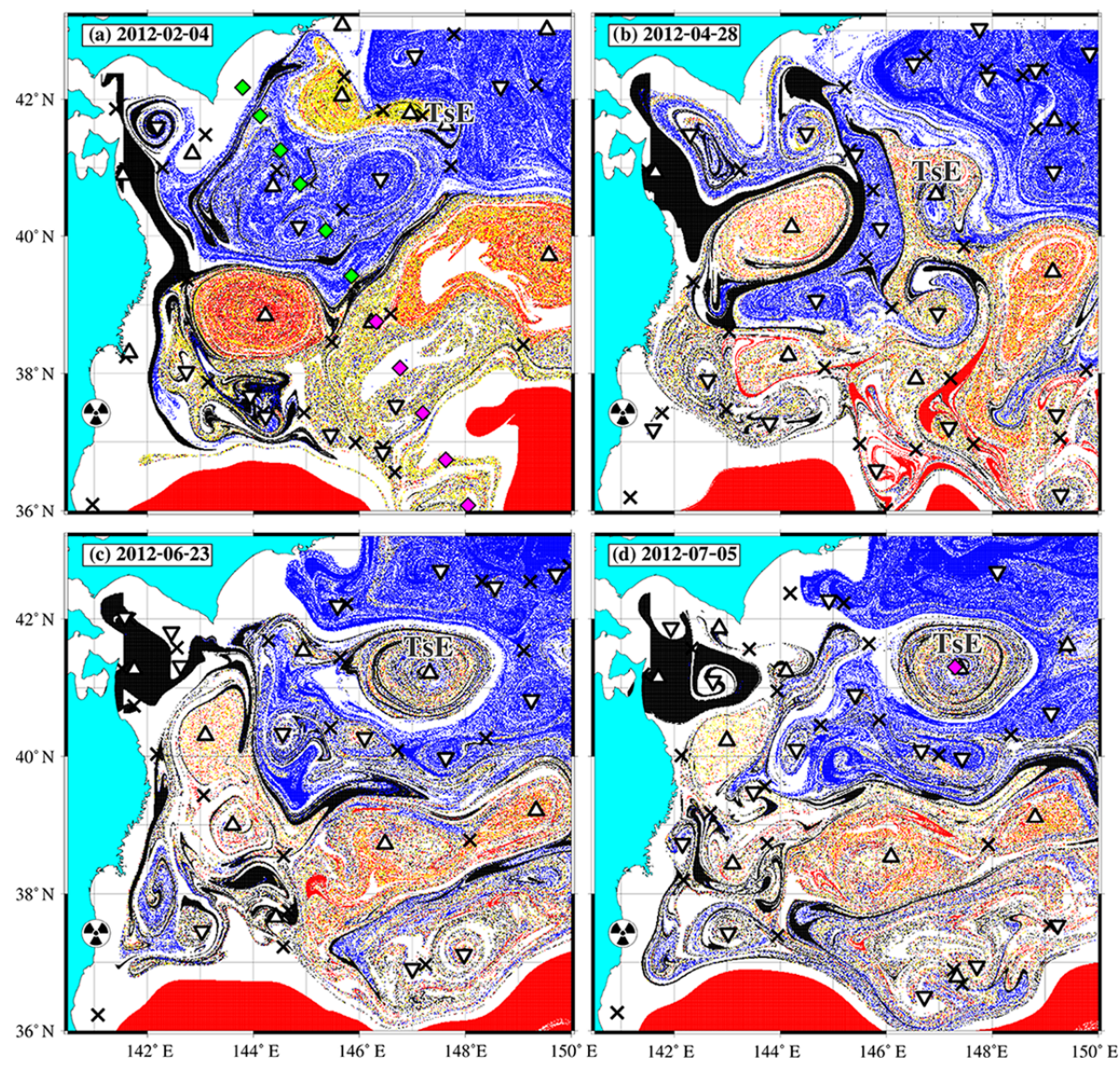

Figure 4. The Lagrangian maps in the study area in the first half of 2012. (a) The locations of stations in the beginning of February with surface seawater samples (collected by Kumamoto et al., 2014) with measured radiocesium concentrations at the background level (the green diamonds) and with higher concentration levels (the magenta diamonds). (b-d) The Lagrangian maps show evolution of the Tsugaru eddy (TsE), which originated on 4 February 2012 (a) after splitting of the HE and was sampled by Budyansky et al. (2015) at station 84 on 5 July 2012 and shown to have increased radiocesium concentrations (the magenta diamond in d).

HE persisted in the area around $42^{\circ} \mathrm{N}, 148^{\circ} \mathrm{E}$ up to the end of January of the next year. It eventually split on 31 January 2012 into two anticyclones.

\subsection{The Tsugaru eddy}

The anticyclonic TsE originated on 4 February 2012 after decay of the HE (the yellow patch with the elliptic point at $42^{\circ} \mathrm{N}, 145.6^{\circ} \mathrm{E}$ in Fig. 4a). The elliptic point at the center of the TsE appeared at $41.8^{\circ} \mathrm{N}, 146.9^{\circ} \mathrm{E}$. Just after its birth, the HE begun to transport its yellow water around the TsE with the core consisted of an Oyashio blue water (Fig. 4b). The strong Subarctic Front is visible in Fig. 4 as a contrast boundary between Oyashio blue water and Fukushima-derived yellow water, with the Tsugaru black water in between.

Seawater samples for radiocesium measurements in the frontal area were collected during the R/V Mirai cruise from 31 January to 5 February 2012 along one of the observation lines of the World Ocean Circulation Experiment (WOCE) in the western Pacific, specifically the
WOCE-P10-P10N line (Kumamoto et al., 2014). We impose on the simulated Lagrangian map in Fig. 4a locations of stations to the north of the Kuroshio Extension $\left(>36^{\circ} \mathrm{N}\right)$ with measured levels of the cesium concentrations. As before, the green diamonds mark locations of those stations, $\mathrm{P} 10-114\left(42.17^{\circ} \mathrm{N}, 143.8^{\circ} \mathrm{E}\right), \mathrm{P} 10-112$ $\left(41.75^{\circ} \mathrm{N}, 144.13^{\circ} \mathrm{E}\right), \mathrm{P} 10-110\left(41.25^{\circ} \mathrm{N}, 144.51^{\circ} \mathrm{E}\right), \mathrm{P} 10$ $108\left(40.76^{\circ} \mathrm{N}, 144.88^{\circ} \mathrm{E}\right), \mathrm{P} 10-106\left(40.08^{\circ} \mathrm{N}, 145.37^{\circ} \mathrm{E}\right)$ and $\mathrm{P} 10-104\left(39.42^{\circ} \mathrm{N}, 145.85^{\circ} \mathrm{E}\right)$, where the cesium concentrations in surface seawater samples were measured by Kumamoto et al. (2014) to be at the background level.

The stations, $\mathrm{P} 10-102\left(38.75^{\circ} \mathrm{N}, 146.32^{\circ} \mathrm{E}\right), \mathrm{P} 10-100$ $\left(38.08^{\circ} \mathrm{N}, 146.77^{\circ} \mathrm{E}\right), \mathrm{P} 10-98\left(37.42^{\circ} \mathrm{N}, 147.2^{\circ} \mathrm{E}\right), \mathrm{P} 10-$ $96\left(36.74^{\circ} \mathrm{N}, 147.63^{\circ} \mathrm{E}\right)$ and $\mathrm{P} 10-94\left(36.08^{\circ} \mathrm{N}, 148.05^{\circ} \mathrm{E}\right)$, where the concentrations were found to be larger (but not exceeding $25.19 \pm 1.24 \mathrm{mBq} \mathrm{kg}^{-1}$ for ${ }^{137} \mathrm{Cs}$ ), are indicated by the magenta diamonds. It is worth stressing a good qualitative correspondence with our simulation results 10 months after the accident in the sense that stations with measured background level are in the area of Oyashio blue waters with 
low risk of being contaminated, whereas stations with comparatively high levels of radiocesium concentrations are in the area of the Fukushima-derived yellow waters with increased risk of contamination.

As to the TsE, it was sampled later, in 5 July 2012, during the cruise of the R/V Professor Gagarinskiy (Budyansky et al., 2015) when it was a comparatively large mesoscale eddy around $150 \mathrm{~km}$ in diameter with the elliptic point at $41.3^{\circ} \mathrm{N}, 147.3^{\circ} \mathrm{E}$ consisting of intermittent strips of blue and yellow waters (Fig. 4d), which were wrapped around during its growth from February to July 2012. Station 84 in that cruise was located near the elliptic point of that eddy (called "G" by Budyansky et al., 2015). The concentrations of ${ }^{137} \mathrm{Cs}$ at the surface and at $100 \mathrm{~m}$ depth were measured as $11 \pm 0.6$ and $18 \pm 1.3 \mathrm{mBq} \mathrm{kg}^{-1}$, respectively, an order of magnitude larger than the background level. As to the ${ }^{134} \mathrm{Cs}$ concentration, it was measured to be smaller, $6.1 \pm 0.4$ and $10.4 \pm 0.7 \mathrm{mBq} \mathrm{kg}^{-1}$, due to a shorter half-lifetime of that isotope. In fact, it was one of the highest cesium concentrations measured inside all the eddy features sampled in the cruise 15 months after the accident.

The maximal concentration of radionuclides was observed, as expected, not at the surface but within subsurface and intermediate water layers $(100-500 \mathrm{~m})$ in the potential density range of 26.5-26.7 due to a convergence and subduction of surface water inside anticyclonic eddies. The corresponding tracking map in Fig. 10c by Budyansky et al. (2015) confirms its genetic link with the TE, and, therefore, a probability of detecting increased cesium concentrations was expected to be comparatively large. We were able to track all the modification of the TsE up to its death on 16 April 2013 in the area around $40^{\circ} \mathrm{N}, 147.5^{\circ} \mathrm{E}$.

\section{Conclusions}

We elaborated a specific Lagrangian methodology for simulating, tracking and documenting the origin and history of water masses in ocean mesoscale features. Integrating advection equations for passive particles in the AVISO velocity field backward in time, we have computed Lagrangian maps clearly demonstrating which waters the mesoscale eddies in the Kuroshio-Oyashio confluence zone were composed of. It allowed the simulation of the ways in which they gained and lost water with a risk of being contaminated by Fukushima-derived radionuclides. We have studied three genetically linked persistent mesoscale anticyclonic eddies in the area, TE, HE and TsE, which were sampled in the $\mathrm{R} / \mathrm{V}$ cruises in 2011 and 2012 and shown to contain higher concentrations of radiocesium isotopes. The simulated Lagrangian maps allowed the documentation and analysis of how they interact and pass radioactive water to each other. The simulated results have been shown to be in a good qualitative correspondence compared with in situ measurements.
We hope that the proposed methodology could be applied to simulate propagation of pollutants after future possible accidents and identify and track contaminated persistent features in the ocean. The Lagrangian methodology seems to be useful, as well, for planning courses of the R/V cruises. It allows not only tracking of mesoscale eddies in the studied area but also identification of the origin of water masses and to estimate a priori concentrations of radionuclides, pollutants or other Lagrangian tracers inside the eddies planned to be sampled.

Data availability. The altimeter products were produced by Ssalto/Duacs and distributed by AVISO, with support from Cnes (http://www.aviso.altimetry.fr/duacs). The drifter data were collected and made freely available by the Global Drifter Program (http://www.aoml.noaa.gov/phod/dac) of the National Oceanic and Atmospheric Administration, NOAA, USA. The data used cover the period up to September 2016

For any questions regarding the simulations data, we encourage the reader to contact the author at uleysky@poi.dvo.ru. There are very large files of a few gigabytes in size that cannot be deposited in a reliable public data repository.

Competing interests. The authors declare that they have no conflict of interest.

Acknowledgements. The methodological part of the work was supported by the Russian Foundation for Basic Research (project no. 16-05-00213) and the simulations were supported by the Russian Science Foundation (project no. 16-17-10025). The altimeter products were distributed by AVISO with support from CNES.

Edited by: M. Hecht

Reviewed by: two anonymous referees

\section{References}

Aoyama, M., Uematsu, M., Tsumune, D., and Hamajima, Y.: Surface pathway of radioactive plume of TEPCO Fukushima NPP1 released ${ }^{134} \mathrm{Cs}$ and ${ }^{137} \mathrm{Cs}$, Biogeosciences, 10, 30673078, https://doi.org/10.5194/bg-10-3067-2013, 2013.

Budyansky, M. V., Uleysky, M. Y., and Prants, S. V.: Detection of barriers to cross-jet Lagrangian transport and its destruction in a meandering flow, Phys. Rev. E, 79, 056215, https://doi.org/10.1103/physreve.79.056215, 2009.

Budyansky, M. V., Goryachev, V. A., Kaplunenko, D. D., Lobanov, V. B., Prants, S. V., Sergeev, A. F., Shlyk, N. V., and Uleysky, M. Y.: Role of mesoscale eddies in transport of Fukushimaderived cesium isotopes in the ocean, Deep-Sea Res. Pt. I, 96, 15-27, https://doi.org/10.1016/j.dsr.2014.09.007, 2015.

Buesseler, K. O., Jayne, S. R., Fisher, N. S., Rypina, I. I., Baumann, H., Baumann, Z., Breier, C. F., Douglass, E. M., George, J., Macdonald, A. M., Miyamoto, H., Nishikawa, J., Pike, S. M., 
and Yoshida, S.: Fukushima-derived radionuclides in the ocean and biota off Japan, P. Natl. Acad. Sci. USA, 109, 5984-5988, https://doi.org/10.1073/pnas.1120794109, 2012.

Haller, G.: Lagrangian Coherent Structures, Annual Rev. Fluid Mech., 47, 137-162, https://doi.org/10.1146/annurev-fluid010313-141322, 2015.

Haza, A. C., Özgökmen, T. M., Griffa, A., Molcard, A., Poulain, P.-M., and Peggion, G.: Transport properties in small-scale coastal flows: relative dispersion from VHF radar measurements in the Gulf of La Spezia, Ocean Dynam., 60, 861-882, https://doi.org/10.1007/s10236-010-0301-7, 2010.

Honda, M. C., Aono, T., Aoyama, M., Hamajima, Y., Kawakami, H., Kitamura, M., Masumoto, Y., Miyazawa, Y., Takigawa, M., and Saino, T.: Dispersion of artificial caesium-134 and -137 in the western North Pacific one month after the Fukushima accident, Geochem. J., 46, e1-e9, 2012.

Huntley, H. S., Lipphardt, B. L., and Kirwan, A. D.: Monitoring and Modeling the Deepwater Horizon Oil Spill: A Record-Breaking Enterprise, chap. Surface Drift Predictions of the Deepwater Horizon Spill: The Lagrangian Perspective, 179-195, American Geophysical Union, Washington, D. C., https://doi.org/10.1029/2011GM001097, 2011.

Inoue, M., Kofuji, H., Hamajima, Y., Nagao, S., Yoshida, K., and Yamamoto, M.: ${ }^{134} \mathrm{Cs}$ and ${ }^{137} \mathrm{Cs}$ activities in coastal seawater along Northern Sanriku and Tsugaru Strait, northeastern Japan, after Fukushima Dai-ichi Nuclear Power Plant accident, J. Environ. Radioactiv., 111, 116-119, https://doi.org/10.1016/j.jenvrad.2011.09.012, 2012a.

Inoue, M., Kofuji, H., Nagao, S., Yamamoto, M., Hamajima, Y., Yoshida, K., Fujimoto, K., Takada, T., and Isoda, Y.: Lateral variation of ${ }^{134} \mathrm{Cs}$ and ${ }^{137} \mathrm{Cs}$ concentrations in surface seawater in and around the Japan Sea after the Fukushima Dai-ichi Nuclear Power Plant accident, J. Environ. Radioactiv., 109, 45-51, https://doi.org/10.1016/j.jenvrad.2012.01.004, 2012b.

Kaeriyama, H., Ambe, D., Shimizu, Y., Fujimoto, K., Ono, T., Yonezaki, S., Kato, Y., Matsunaga, H., Minami, H., Nakatsuka, S., and Watanabe, T.: Direct observation of ${ }^{134} \mathrm{Cs}$ and ${ }^{137} \mathrm{Cs}$ in surface seawater in the western and central North Pacific after the Fukushima Dai-ichi nuclear power plant accident, Biogeosciences, 10, 4287-4295, https://doi.org/10.5194/bg-104287-2013, 2013.

Kaeriyama, H., Shimizu, Y., Ambe, D., Masujima, M., Shigenobu, Y., Fujimoto, K., Ono, T., Nishiuchi, K., Taneda, T., Kurogi, H., Setou, T., Sugisaki, H., Ichikawa, T., Hidaka, K., Hiroe, Y., Kusaka, A., Kodama, T., Kuriyama, M., Morita, H., Nakata, K., Morinaga, K., Morita, T., and Watanabe, T.: Southwest Intrusion of ${ }^{134} \mathrm{Cs}$ and ${ }^{137} \mathrm{Cs}$ Derived from the Fukushima Dai-ichi Nuclear Power Plant Accident in the Western North Pacific, Environ. Sci. Technol., 48, 3120-3127, https://doi.org/10.1021/es403686v, 2014.

Kameník, J., Dulaiova, H., Buesseler, K. O., Pike, S. M., and Št'astná, K.: Cesium-134 and 137 activities in the central North Pacific Ocean after the Fukushima Dai-ichi Nuclear Power Plant accident, Biogeosciences, 10, 6045-6052, https://doi.org/10.5194/bg-10-6045-2013, 2013.

Kawai, H.: Hydrography of the Kuroshio Extension, in: Kuroshio: Physical Aspects of the Japan Current, edited by: Stommel, H. M. and Yoshida, K., University of Washington Press, Seattle, 235-352, 1972.
Koshel', K. V. and Prants, S. V.: Chaotic advection in the ocean, Physics-Uspekhi, 49, 1151-1178, https://doi.org/10.1070/PU2006v049n11ABEH006066, 2006.

Kumamoto, Y., Aoyama, M., Hamajima, Y., Aono, T., Kouketsu, S., Murata, A., and Kawano, T.: Southward spreading of the Fukushima-derived radiocesium across the Kuroshio Extension in the North Pacific, Scientific Reports, 4, 1-9, https://doi.org/10.1038/srep04276, 2014.

Mancho, A. M., Small, D., and Wiggins, S.: A tutorial on dynamical systems concepts applied to Lagrangian transport in oceanic flows defined as finite time data sets: Theoretical and computational issues, Phys. Rep., 437, 55-124, https://doi.org/10.1016/j.physrep.2006.09.005, 2006.

Mezić, I., Loire, S., Fonoberov, V. A., and Hogan, P.: A New Mixing Diagnostic and Gulf Oil Spill Movement, Science, 330, 486-489, https://doi.org/10.1126/science.1194607, 2010.

Nencioli, F., d'Ovidio, F., Doglioli, A. M., and Petrenko, A. A.: Surface coastal circulation patterns by in-situ detection of Lagrangian coherent structures, Geophys. Res. Lett., 38, L17604, https://doi.org/10.1029/2011g1048815, 2011.

Oikawa, S., Takata, H., Watabe, T., Misonoo, J., and Kusakabe, M.: Distribution of the Fukushima-derived radionuclides in seawater in the Pacific off the coast of Miyagi, Fukushima, and Ibaraki Prefectures, Japan, Biogeosciences, 10, 5031-5047, https://doi.org/10.5194/bg-10-5031-2013, 2013.

Olascoaga, M. J. and Haller, G.: Forecasting sudden changes in environmental pollution patterns, P. Natl. Acad. Sci. USA, 109, 4738-4743, https://doi.org/10.1073/pnas.1118574109, 2012.

Olascoaga, M. J., Beron-Vera, F. J., Haller, G., Triñanes, J., Iskandarani, M., Coelho, E. F., Haus, B. K., Huntley, H. S., Jacobs, G., Kirwan, A. D., Lipphardt, B. L., Özgökmen, T. M., Reniers, A. J. H. M., and Valle-Levinson, A.: Drifter motion in the Gulf of Mexico constrained by altimetric Lagrangian coherent structures, Geophys. Res. Lett., 40, 61716175, https://doi.org/10.1002/2013g1058624, 2013.

Povinec, P. P., Hirose, K., and Aoyama, M.: Fukushima Accident: Radioactivity Impact on the Environment, Elsevier, Amsterdam, https://doi.org/10.1016/B978-0-12-408132-1.01001-9, 2013.

Prants, S. V.: Dynamical systems theory methods to study mixing and transport in the ocean, Phys. Scripta, 87, 038115, https://doi.org/10.1088/0031-8949/87/03/038115, 2013.

Prants, S. V.: Chaotic Lagrangian transport and mixing in the ocean, The European Physical Journal Special Topics, 223, 2723-2743, https://doi.org/10.1140/epjst/e2014-02288-5, 2014.

Prants, S. V., Budyansky, M. V., Ponomarev, V. I., and Uleysky, M. Y.: Lagrangian study of transport and mixing in a mesoscale eddy street, Ocean Model., 38, 114-125, https://doi.org/10.1016/j.ocemod.2011.02.008, 2011a.

Prants, S. V., Uleysky, M. Y., and Budyansky, M. V.: Numerical simulation of propagation of radioactive pollution in the ocean from the Fukushima Dai-ichi nuclear power plant, Dokl. Earth Sci., 439, 1179-1182, https://doi.org/10.1134/S1028334X11080277, $2011 \mathrm{~b}$.

Prants, S. V., Ponomarev, V. I., Budyansky, M. V., Uleysky, M. Y., and Fayman, P. A.: Lagrangian analysis of mixing and transport of water masses in the marine bays, Izvestiya, Atmos. Ocean. Phys., 49, 82-96, https://doi.org/10.1134/S0001433813010088, 2013. 
Prants, S. V., Budyansky, M. V., and Uleysky, M. Yu.: Lagrangian study of surface transport in the Kuroshio Extension area based on simulation of propagation of Fukushimaderived radionuclides, Nonlin. Processes Geophys., 21, 279-289, https://doi.org/10.5194/npg-21-279-2014, 2014.

Prants, S. V., Lobanov, V. B., Budyansky, M. V., and Uleysky, M. Y.: Lagrangian analysis of formation, structure, evolution and splitting of anticyclonic Kuril eddies, Deep-Sea Res. Pt. I, 109, 6175, https://doi.org/10.1016/j.dsr.2016.01.003, 2016.

Samelson, R. M. and Wiggins, S.: Lagrangian Transport in Geophysical Jets and Waves: The Dynamical Systems Approach, vol. 31 of Interdisciplinary Applied Mathematics, Springer Science+Business Media, LLC, https://doi.org/10.1007/978-0-38746213-4, 2006
Tsumune, D., Tsubono, T., Aoyama, M., and Hirose, K.: Distribution of oceanic ${ }^{137} \mathrm{Cs}$ from the Fukushima Daiichi Nuclear Power Plant simulated numerically by a regional ocean model, J. Environ. Radioactiv., 111, 100-108, https://doi.org/10.1016/j.jenvrad.2011.10.007, 2012.

Tsumune, D., Tsubono, T., Aoyama, M., Uematsu, M., Misumi, K., Maeda, Y., Yoshida, Y., and Hayami, H.: One-year, regionalscale simulation of ${ }^{137} \mathrm{Cs}$ radioactivity in the ocean following the Fukushima Dai-ichi Nuclear Power Plant accident, Biogeosciences, 10, 5601-5617, https://doi.org/10.5194/bg-10-56012013, 2013. 